\title{
Fuzzy Transportation Problem Using Symmetric Hexagonal Fuzzy Numbers
}

\author{
A.SahayaSudha ${ }^{1}$ and K.R. Vijayalakshmi ${ }^{2}$ \\ Department of Mathematics Nirmala College for Women Coimbatore, India
}

\begin{abstract}
In this paper, symmetric hexagonal Fuzzy Transportation Problem (FTP) is introduced with fuzzy demand and supply and an optimal solution is obtained for the same. This is done by using a numerical problem which clearly defines the fuzzy transportation problem.
\end{abstract}

Keywords: Ranking, Symmetric Hexagonal fuzzy number, Transportation problem..

\section{Introduction}

In ranking fuzzy numbers many methods have been presented till now, each one is rated based on its special standards proportion and characteristics of fuzzy number. Fuzzy number ranking was first considered by Jain [8]. Bellman and Zedeh [2] discussed about decision making in fuzzy environment. Amarpreetkaur and Amit kumar [1] proposed a new method for solving fuzzy transportation problem using ranking function. Nareshkumar and Kumar Ghuru [12] solved a fuzzy transportation problem using symmetric triangular fuzzy number. Rajarajeswari and Sahayasudha et.al.,[13] introduced a new operation on hexagonal fuzzy number. Chanas et. al., [3] developed a method for solving transportation problems with fuzzy supplies and demands via the parametric programming technique using the Belmann- Zadeh criterion [2]. Chanas and Kuchta [4] introduced a method for solving a transportation problem with fuzzy cost coefficients by transforming the given problem to a bicriterial transportation problem with crisp objective function which provides only crisp solution to the given transportation problem. Liu an Kao [11] described a method for solving transportation problem based on extensive principle. Gani and Razak [6] presented a two stage cost minimizing fuzzy transportation problem (FTP) in which supplies and demands are trapezoidal fuzzy numbers. Since then several methods have been proposed by various researchers which includes ranking fuzzy numbers using maximizing and minimizing set. In this paper, we introduced fuzzy transportation problem with symmetric hexagonal fuzzy demand and supply and obtained an optimal solution of the same.

\subsection{Fuzzy set [ 9 ]}

\section{Preliminaries}

A fuzzy set is characterized by a membership function mapping element of a domain, space, or the universe of discourse $\mathrm{X}$ to the unit interval [0,1].(i.e.) $A=\left\{\left(x, \mu_{A}(x)\right) ; x \in X\right\}$. Here $\mu_{A}: X \rightarrow[0,1]$ is a mapping called the degree of membership function of the fuzzy set A and $\mu_{A}(x)$ is called the membership value of $x \in X$ in the fuzzy set $A$. These membership grades are often represented by real numbers ranging from $[0,1]$.

\subsection{Normal fuzzy set:}

A fuzzy set A of the universe of discourse $\mathrm{X}$ is called a normal fuzzy set implying that there exist at least one $\mathrm{x} \in \mathrm{X}$ such that $\mu_{A}(x)=1$.

\subsection{Fuzzy number [10]}

A fuzzy set $A$ defined on the set of real numbers $\mathrm{R}$ is said to be a fuzzy number if its membership function $\mu_{A}: R \rightarrow[0,1]$ has the following properties

i) $A$ must be a normal fuzzy set.

ii) $\alpha_{A}$ must be a closed interval for every $\alpha \in(0,1]$.

iii) The support of $A,{ }^{0+} A$, must be bounded.

\subsection{Hexagonal Fuzzy Number [13]}

A fuzzy number $\tilde{A}_{H}$ is a hexagonal fuzzy number denoted by $\widetilde{A}_{H}=\left(\mathrm{a}_{1}, \mathrm{a}_{2}, \mathrm{a}_{3}, \mathrm{a}_{4}, \mathrm{a}_{5}, \mathrm{a}_{6}\right)$ where $\mathrm{a}_{1}, \mathrm{a}_{2}, \mathrm{a}_{3}, \mathrm{a}_{4}, \mathrm{a}_{5}$ and $\mathrm{a}_{6}$ are real numbers and its membership function is given below, 


$$
\mu_{\tilde{A}_{H}}(x)= \begin{cases}\frac{1}{2}\left(\frac{x-a_{1}}{a_{2}-a_{1}}\right), & \text { for } a_{1} \leq x \leq a_{2} \\ \frac{1}{2}+\frac{1}{2}\left(\frac{x-a_{2}}{a_{3}-a_{2}}\right), & \text { for } a_{2} \leq x \leq a_{3} \\ 1, & \text { for } a_{3} \leq x \leq a_{4} \\ 1-\frac{1}{2}\left(\frac{x-a_{4}}{a_{5}-a_{4}}\right), & \text { for } a_{4} \leq x \leq a_{5} \\ \frac{1}{2}\left(\frac{a_{6}-x}{a_{6}-a_{5}}\right), & \text { for } a_{5} \leq x \leq a_{6} \\ 0, & \text { otherwise }\end{cases}
$$

\subsection{Ranking of Hexagonal Fuzzy Numbers [13]}

An efficient approach for comparing the fuzzy numbers is by the use of a ranking function $R: F(R) \rightarrow$ $R$, where $F(R)$ is a set of fuzzy numbers defined on set of real numbers, which maps each fuzzy number into a real number, where a natural order exists

For every $\tilde{A}_{H}=\left(a_{1}, a_{2}, a_{3}, a_{4}, a_{5}, a_{6}\right) \in \mathrm{F}(\mathrm{R})$, the ranking function $\mathrm{R}: \mathrm{F}(\mathrm{R}) \rightarrow \mathrm{R}$ defined as

$$
R\left(\tilde{A}_{H}\right)=\left(\frac{2 a_{1}+3 a_{2}+4 a_{3}+4 a_{4}+3 a_{5}+2 a_{6}}{18}\right)\left(\frac{5}{18}\right)
$$

\subsection{Symmetric Triangular Fuzzy number [4]}

If $a^{(2)}=a^{(3)}$, then the triangular fuzzy number $\mathrm{A}=\left(a^{(1)}{ }_{y} a^{(2)}{ }_{3} a^{(3)}\right)$ is called symmetric triangular fuzzy number. It is denoted by $\mathrm{A}=\left(a^{(1)}, a^{(2)}\right)$, where $a^{(1)}$ is Core (A), $a^{(2)}$ is left width and right width of C.

\subsection{Symmetric trapezoidal fuzzy number [7]}

A fuzzy set $\bar{A}$ on $R$ is called a symmetric trapezoidal fuzzy number if its membership function is defined as follows:

$$
\mu_{\tilde{A}_{H}}(x)= \begin{cases}\left(\frac{x-\left(a^{L}-\alpha\right)}{\alpha}\right), & \text { for } a^{L}-\alpha \leq x \leq a^{L} \leq x \leq a^{U} \\ 1, & \text { for } a^{U} \leq x \leq a^{U}+\alpha \\ \left(\frac{\left(a^{U}+\alpha\right)-x}{\alpha}\right), & \text { otherwise }\end{cases}
$$

We denote a symmetric trapezoidal fuzzy number $\overline{\mathrm{A}}=\left(\mathrm{a}^{\mathrm{L}}, \mathrm{a}^{\mathrm{U}}, \alpha, \alpha\right)$ and the set of all symmetric trapezoidal fuzzy numbers by $\mathrm{F}(\mathrm{R})$ 


\section{Symmetric Hexagonal Fuzzy Number}

A symmetric hexagonal fuzzy number

$$
\tilde{\mathrm{A}}_{H=} a_{L}-s-t, a_{L}-s, a_{L}, a_{U}, a_{U}+s, a_{U}+s+t
$$

Where $a_{L}, a_{U}, s$ and $t$ are real numbers and its membership function is defined as

$$
\mu_{\tilde{A}_{H}}(x)= \begin{cases}\frac{1}{2}\left(\frac{x-\left(a_{L}-s-t\right)}{t}\right), & \text { for } a_{L}-s-t \leq x \leq a_{L}-s \\ \frac{1}{2}+\frac{1}{2}\left(\frac{x-\left(a_{L}-s\right)}{s}\right), & \text { for } a_{L}-s \leq x \leq a_{L} \\ 1-\frac{1}{2}\left(\frac{x-a_{U}}{s}\right), & \text { for } a_{L} \leq x \leq a_{U} \leq x \leq a_{U}+s \\ \frac{1}{2}\left(\frac{\left.a_{U}+s+t\right)-x}{t}\right), & \text { for } a_{U}+s \leq x \leq a_{u}+s+t \\ 0, & \text { otherwise }\end{cases}
$$

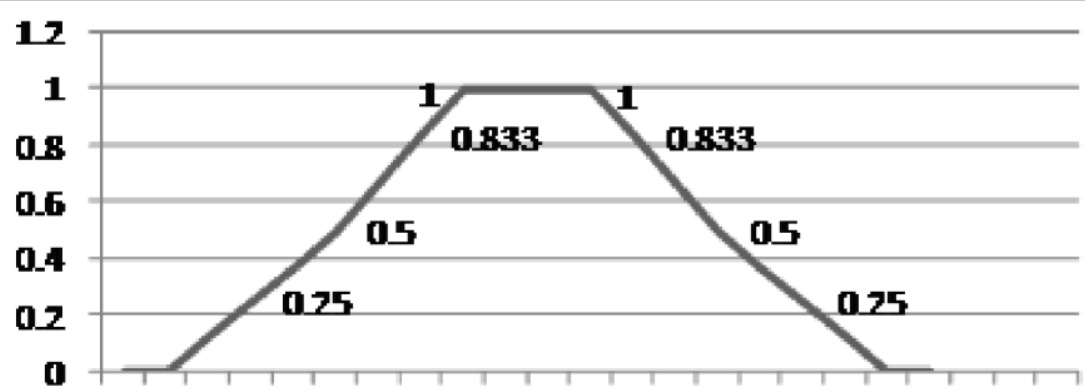

012345673910111213141516171819

Fig. 3. 1. Graphical representation of the symmetrical hexagonal fuzzy number

IV. Mathematical Formulation Of Fuzzy Transportation Problem

The mathematical models of fuzzy transportation problem is to minimize the total transportation cost from $\mathrm{m}$ sources to $\mathrm{n}$ destinations is as follows

$$
\begin{aligned}
& \text { Minimize } \tilde{Z}= \sum_{i=1}^{m} \sum_{j=1}^{n} \tilde{c}_{i j} \tilde{x}_{i j} \\
& \text { subject to } \sum_{j=1}^{n} \tilde{x}_{i j}=\tilde{a}_{i} \quad, \quad i=1,2,3, \ldots \ldots \ldots, m \\
& \sum_{i=1}^{n} \tilde{x}_{i j}=\tilde{b}_{j} \quad, \quad j=1,2,3, \ldots \ldots \ldots, n \\
& \sum_{i=1}^{n} \tilde{a}_{i}=\tilde{b}_{j} \quad, \quad i=1,2,3, \ldots \ldots \ldots, m ; \quad j=1,2,3 \ldots \ldots \ldots . . . . . . . . . . \\
& \text { and } \quad \tilde{x}_{i j} \geq 0 \quad \text { for all } i \text { and } j .
\end{aligned}
$$

where $\tilde{c}_{i j}$ is the fuzzy unit transportation cost from $\mathrm{i}^{\text {th }}$ source to the $\mathrm{j}^{\text {th }}$ destination. 
Table - 4.1.1 Fuzzy transportation table

\begin{tabular}{|c|c|c|c|c|c|c|}
\hline \multirow{7}{*}{$\begin{array}{l}\mathrm{S} \\
\mathrm{O} \\
\mathrm{U} \\
\mathrm{R} \\
\mathrm{C} \\
\mathrm{E} \\
\mathrm{S}\end{array}$} & \multicolumn{6}{|c|}{ DESTINATION } \\
\hline & & 1 & 2 & $\ldots$ & $\mathrm{N}$ & Supply \\
\hline & 1 & $\tilde{c}_{11}$ & $\tilde{c}_{12}$ & $\ldots$ & $\tilde{c}_{1 n}$ & $\tilde{a}_{1}$ \\
\hline & 2 & $\tilde{c}_{21}$ & $\tilde{c}_{22}$ & $\cdots$ & $\tilde{c}_{2 n}$ & $\tilde{a}_{2}$ \\
\hline & & . & . & $\ldots$ & & . \\
\hline & M & $\tilde{c}_{m 1}$ & $\tilde{c}_{m 2}$ & $\cdots$ & $\tilde{c}_{m n}$ & $\tilde{a}_{m}$ \\
\hline & Demand & $\tilde{b}_{1}$ & $\tilde{b}_{2}$ & $\cdots$ & $\tilde{b}_{n}$ & \\
\hline
\end{tabular}

\subsection{Fuzzy Version of Best candidate Method}

Step:1 From the Fuzzy Transportation table, if the total supply is equal to the total demand, then the matrix is balanced. Then proceed to Step 2. If the total supply is not equal to the total demand, a dummy row or column is added as per the need to make the supply equal to the demand. So the transportation cost in this row or column will be assigned to zero.

Step 2: The best candidate for minimizing problems to the minimum cost and maximizing profit to the maximum cost is selected. Therefore this step is done by electing best candidate in each row.

Step 3: Identify the row with the smallest cost candidate from the chosen combination. Then allocate the demand and the supply as much as possible to the variable with the least unit cost in the selected row or column. Also the supply and demand is adjusted by crossing out the row/column and then assign to zero.

Step 4: The process is repeated until an optimum basic feasible solution is obtained.

\subsection{Numerical example}

Consider the following fuzzy transportation problem. A company has three factories $\mathrm{O}_{1}, \mathrm{O}_{2}, \mathrm{O}_{3}$ and four outlets $D_{1}, D_{2}, D_{3}$, and $D_{4}$. The fuzzy transportation cost for unit quantity of the product form $\mathrm{i}^{\text {th }}$ source to $\mathrm{j}^{\text {th }}$ outlet is $C_{i j}$ where

$$
\left[\tilde{C}_{i j}\right]_{3 \times 4}=\left[\begin{array}{cccc}
(1,2,3,4,5,6) & (2,4,6,8,10,12) & (1,3,5,7,9,11) & (3,6,9,12,15,18) \\
(6,7,8,9,10,1) & (3,4,5,6,7,8) & (7,8,9,10,11,12) & (5,6,7,8,9,10) \\
(9,10,11,12,13,14) & (6,8,10,12,14,16) & (4,6,8,10,12,14) & (8,12,16,20,24,28)
\end{array}\right]
$$

The production quantities per month at $O_{1}, O_{2}, O_{3}$ are $(8,10,12,14,16,18),(5,7,9,11,13,15)$ and $(6,8,10,12,14,16)$ tons respectively. The demand per month for $D_{1}, D_{2}, D_{3}$ and $D_{4}$ are $(1,3,5,7,9,11)$ $(2,6,10,14,18,22),(1,4,7,10,13,16)$ and $(2,4,6,8,10,12)$ respectively.

\section{Solution:}

Step 1: Construct a fuzzy transportation table for the given transportation problem and then, convert it into a balanced one. Here the given problem is a balanced one so we move on to step 2 .

Table 4.2.1 Fuzzy Transportation Problem

\begin{tabular}{|l|l|l|l|l|l|}
\hline & Outlets & $\mathrm{D}_{2}$ & $\mathrm{D}_{4}$ & Supply \\
\hline Factory & $\mathrm{D}_{1}$ & $(2,4,6,8,10,12)$ & $(1,3,5,7,9,11)$ & $(3,6,9,12,15,18)$ & $(8,10,12,14,16,18)$ \\
\hline$O_{1_{3}}$ & $(1,2,3,4,5,6)$ & $(3,4,5,6,7,8)$ & $(7,8,9,10,11,12)$ & $(5,6,7,8,9,10)$ & $(5,7,9,11,13,15)$ \\
\hline$O_{\mathbf{2}_{3}}$ & $(6,7,8,9,10,11)$ & & & & $(8,12,16,20,24,28)$ \\
\hline$O_{3_{3}}$ & $(9,10,11,12,13,14)$ & $(6,8,10,12,14.16)$ & $(4,6,8,10,12,14)$ & $(6,8,10,12,14,16)$ \\
\hline Demand & $(1,3,5,7,9,11)$ & $(2,6,10,14,18,22)$ & $(1,4,7,10,13,16)$ & $(2,4,6,8,10,12)$ & \\
\hline
\end{tabular}

Now using hexagonal ranking method [2.5] in the symmetrical hexagonal fuzzy transportation problem, it is further converted into a transportation problem 


$\left[\begin{array}{ccccc}R(1,2,3,4,5,6) & R(2,4,6,8,10,12) & R(1,3,5,7,9,11) & R(3,6,9,12,15,18) & R(8,10,12,14,16,18) \\ R(6,7,8,9,10,11) & R(3,4,5,6,7,8,) & R(7,8,9,10,11,12) & R(5,6,7,8,9,10) & R(5,7,9,11,13,15 \\ R(9,10,11,12,13,14) & R(6,8,10,12,14,16) & R(4,6,8,10,12,14) & R(8,12,16,20,24,28) & R(6,8,10,12,14,16\end{array}\right]$

Now we calculate $\mathrm{R}(1,2,3,4,5,6)$ by applying the ranking method.

\section{Similarly}

$$
\begin{gathered}
R\left(\tilde{A}_{H}\right)=\left(\frac{2 a_{1}+3 a_{2}+4 a_{3}+4 a_{4}+3 a_{5}+2 a_{6}}{18}\right)\left(\frac{5}{18}\right) \\
\mathrm{R}(1,2,3,4,5,6)=\left(\frac{2+6+12+16+15+12}{18}\right)\left(\frac{5}{18}\right)=0.97
\end{gathered}
$$

$$
\begin{array}{llll}
\mathrm{R}(2,4,6,8,10,12)=1.94 & \multicolumn{1}{c}{\mathrm{R}(1,3,5,7,9,11)=1.6} & \mathrm{R}(3,6,9,12,15,18)=2.9 & \mathrm{R}(8,10,12,14,16,18)=3 \\
\mathrm{R}(6,7,8,9,10,11)=2.36 & \mathrm{R}(3,4,5,6,7,8)=1.52 & \mathrm{R}(7,8,9,10,11,12)=2.63 & \mathrm{R}(5,6,7,8,9,10)=2 \\
\mathrm{R}(5,7,9,11,13,15)=2.63 & \mathrm{R}(9,10,11,12,13,14)=3.19 & \mathrm{R}(6,8,10,12,14,16)=3.05 & \mathrm{R}(4,6,8,10,12,14)=2.5 \\
\mathrm{R}(8,12,16,20,24,28)=5 & \mathrm{R}(6,8,10,12,14,16)=3 & \mathrm{R}(1,3,5,7,9,11)=1.66 & \mathrm{R}(2,6,10,14,18,22)=3.3 \\
\mathrm{R}(1,4,7,10,13,16)=2.33 & \mathrm{R}(2,4,6,8,10,12)=1.94 & &
\end{array}
$$

\begin{tabular}{|c|c|c|c|c|c|}
\hline & \multicolumn{5}{|c|}{ Outlets } \\
\hline Customers & $\overline{D_{1}}$ & $\mathrm{D}_{2}$ & $\mathrm{D}_{3}$ & $\mathrm{D}_{4}$ & Supply \\
\hline$O_{1}$ & 0.97 & 1.94 & 1.6 & 2.9 & 3.6 \\
\hline $\mathrm{O}_{2}$ & 2.36 & & 2.63 & 2 & 2.63 \\
\hline $\mathrm{O}_{3}$, & 3.19 & 3.05 & & 5 & 3.0 \\
\hline Demand & 1.66 & 3.3 & 2.33 & 1.94 & \\
\hline
\end{tabular}

Fuzzy transportation problem converted to normal transportation problem is given below

Table 4.2 .2 Normal transportation Problem

\begin{tabular}{|l|l|l|l|l|l|}
\hline & Outlets & \multicolumn{5}{l|}{} \\
\hline Customers & $\mathrm{D}_{1}$ & $\mathrm{D}_{2}$ & $\mathrm{D}_{3}$ & $\mathrm{D}_{4}$ & Supply \\
\hline$O_{1_{3}}$ & 0.97 & 1.94 & 1.6 & 2.9 & 3.6 \\
\hline$O_{2_{3}}$ & 2.36 & 1.52 & 2.63 & 2 & 2.63 \\
\hline$O_{3_{a}}$ & 3.19 & 3.05 & 2.5 & 5 & 3.0 \\
\hline Demand & 1.66 & 3.3 & 2.33 & 1.94 & \\
\hline
\end{tabular}

Step 2: Elect the candidates according to each row and column and then by using BCM, we determine the best combination that will produce the lowest total weight of the costs.

Table - 4.2.3. Table with Selected Candidates

Step 3: Identify the row with the smallest cost candidate from the chosen combination and allocate the demand and supply and also adjusted demand/supply by crossing out the row/column to be then assigned to zero. 
Table - 4.2.4. Final allocation table using best candidate method

\begin{tabular}{|c|c|c|c|c|c|}
\hline & \multicolumn{5}{|c|}{ Outlets } \\
\hline Customers & $\mathrm{D}_{1}$ & $\mathrm{D}_{2}$ & $\mathrm{D}_{3}$ & $\mathrm{D}_{4}$ & Supply \\
\hline$O_{1}$ & 1.66 & $\begin{array}{l}0.67 \\
1.94\end{array}$ & 1.6 & $\begin{array}{l}1.27 \\
2.9\end{array}$ & $\begin{array}{l}1.27 \\
1.94 \\
3.6\end{array}$ \\
\hline $\mathrm{O}_{2}$ & 2.36 & 1.52 & 2.63 & 2 & 2.63 \\
\hline $\mathrm{O}_{3}$ & 3.19 & 3.05 & 2.33 & $\begin{array}{l}\mathbf{0 . 6 7} \\
5\end{array}$ & $\begin{array}{l}9.67 \\
3.0\end{array}$ \\
\hline Demand & 1.66 & $\begin{array}{l}3.3 \\
0.67\end{array}$ & 2.33 & $\begin{array}{l}1.94 \\
0.67\end{array}$ & \\
\hline
\end{tabular}

Step: 4 The optimal solution using best candidate method is given as follows:

Minimize $Z=0.97 \times 1.66+1.94 \times 0.67+1.52 \times 2.63+2.5 \times 2.33+2.9 \times 1.27 \times 5 \times 0.67$

Minimize $Z=1.61+1.29+3.99+5.8+3.68+3.35=19.72$

\section{Conclusion}

In this paper a new membership function for symmetric hexagonal fuzzy number is defined. The transportation cost source and demands are represented by symmetric hexagonal fuzzy numbers. Here the Best candidate method and centroid ranking to transform the fuzzy transportation in to a crisp transportation problem is used and finally the total optimal cost is arrived.

\section{References}

[1] Amarpreet Kaur ,Amit Kumar, A new method for solving fuzzy transportation problem using Ranking function Applied Mathematical Vol 35(12), 5622-5661,(2011).

[2] Bellman, R. E., and , L. A., Zadeh,. Decision making in a fuzzy environment. Management. Sci. 17B, 141-164,(1970)

[3] Chanas, W.Kolodziejczyk and A. Machaj, A fuzzy approach to the transportation problem, Fuzzy Sets and Systems, 13, 211221(1984).

[4] Chanas and D. Kuchta, A concept of the optimal solution of the transportation problem with fuzzy cost coefficients, Fuzzy Sets and systems, 82, 299-305(1996).

[5] Chen S.H, Rank in fuzzy numbers with maximizing set and minimizing set, Fuzzy sets and systems 17, 113-129 (1985).

[6] A Gain, K.A. Razak, Two stage fuzzy transportation problem, J. Phys. Sci.10, 63- 69(2006).

[7] K.Ganesan, P. Veeramani, Fuzzy linear programming with trapezoidal fuzzy numbers, Ann. Oper. Res. 143 (1),305-315(2006).

[8] Jain .R Decision making in the presence of fuzzy variables, IEEE Transactions on systems, Man and Cybernetics 6, 698-703(1976)

[9] Klir George J and Bo Yuan, Fuzzy sets and Fuzzy logic: Theory and Applications, Prentice Hallof India, (1997).

[10] Kaufmann. A, Gupta, M. M.,Fuzzy mathematical models in engineering and Management Science. Elsevier Science Publishers, Amsterdam, Netherlands, (1988).

[11] S.T.Liu, C. Kao, Solving fuzzy transportation problem based on extension principle, European J. Per. Res.153, 661-674(2004).

[12] Nareshkumar and Kumara Ghuru solving fuzzy transportation problem using symmetric triangular fuzzy number International Journal of Advanced Research in Mathematics and Applications Pages:74-83, (2014)

[13] Rajerajeswari, P and Sahaya Sudha. A and Karthika. R. A new Operations on hexagonal fuzzy number International Journal of Fuzzy Logic Systems (IJFLS) Vol.3, No.3. pp 15- 26 (2013). 